\title{
Prevalência de anticorpos para o vírus da Influenza Equiina, subtipo H3N8, em equíídeos apreendidos no Estado do Rio de Janeiro
}

\author{
Antibody prevalence of Equine Influenza virus, subtype H3N8, in equids \\ apprehended on Rio de Janeiro State, Brazil
}

\author{
Gabrielle Sales de Oliveira ${ }^{1}$ Paula Amorim Schiavo ${ }^{1}$ \\ Carlos Mazur ${ }^{2}$ Cláudio de Moraes Andrade ${ }^{3}$
}

\begin{abstract}
$O$ vírus Influenza A, subtipo H3N8, é o agente etiológico da Influenza Eqüina, responsável por diversas epidemias e endemias respiratórias em nível mundial, inclusive no Estado do Rio de Janeiro, Brasil. O objetivo deste trabalho foi avaliar a importância de eqüídeos errantes, como fontes de infecção do vírus Influenza, subtipo H3N8. A enquete foi realizada a partir da pesquisa de anticorpos específicos para este vírus em 1106 soros analisados através da prova de inibição da hemaglutinação. O elevado percentual $(35,9 \%)$ de animais soropositivos encontrados evidencia seu papel como uma importante fonte de infecção deste vírus para o rebanho eqüino nacional.
\end{abstract}

Palavras-chave: eqüídeos, influenza, H3N8, sorologia.

\section{ABSTRACT}

The Influenza virus type A, subtype H3N8, is the etiological agent of the Equine Influenza, responsible for several epidemics and endemic respiratory diseases in world level, besides in the Rio de Janeiro State, Brazil. The objective of this work was to evaluate the role of errant equids, as infectious sources of the Influenza virus, subtype H3N8. The survey was performed from the research of specific antibodies for this virus in 1106 sera analyzed by the inhibition of the hemagglutination test. The high percentile $(35,9 \%)$ of seropositive animals found in this study evidenced its importance as infectious sources of the Influenza virus, subtype H3N8, to the national equine flock.

Key words: equids, influenza, H3N8, serology.
A Influenza Eqüina se destaca dentre as inúmeras doenças que podem ser consideradas de risco para a eqüinocultura, caracterizada como uma síndrome respiratória que afeta eqüídeos em geral, com distribuição mundial. Essa infecção pode ser fatal para asnos, potros, animais mantidos em más condições zootécnicas, não vacinados, e lactentes que não ingeriram o colostro (MILLER, 1965). A Influenza é considerada uma das doenças respiratórias economicamente mais importante para eqüídeos, em diversos países. Reconhecida entre os criadores, há séculos, a Influenza é uma doença viral altamente contagiosa caracterizada, principalmente, por febre, depressão, descarga nasal e, conseqüentemente, queda de performance física (TIMONEY, 1996).

$\mathrm{O}$ vírus da Influenza Eqüina pertence à família Orthomyxoviridae, gênero Influenzavirus A e apresenta dois subtipos: H7N7 e H3N8 (ACHA \& SZYFRIES, 2003). Desde 1980, tanto nos EUA como na Europa não há confirmações de casos de influenza eqüina causados pelo subtipo H7N7; todavia, o subtipo H3N8 tem sido relacionado a vários casos de doença respiratórias endêmicas e epidêmicas em cavalos de todo o mundo (TIMONEY, 1996). O vírus da influenza eqüina, subtipo $\mathrm{H} 3 \mathrm{~N} 8$, encontra-se disseminado em várias regiões do Brasil, inclusive no Estado do Rio

${ }^{1}$ Universidade Federal Rural do Rio de Janeiro (UFRRJ), Seropédica, RJ, Brasil.

${ }^{2}$ Instituto de Veterinária, UFRRJ, UFRRJ, Br 465, Km 07, 23890-000, Seropédica, RJ, Brasil. E-mail: mazur@ufrrj.br. Autor para correspondência.

${ }^{3}$ Instituto de Veterinária, UFRRJ, Seropédica, RJ, Brasil. 
de Janeiro, onde foram descritos surtos de influenza eqüina em 1963, 1969, 1985 e 2001 (ANDREWS et al., 1978; CUNHA, 1970; CUNHA et al., 1986; LOUREIRO, 2004).

O objetivo deste trabalho foi avaliar a importância dos eqüídeos errantes como possíveis fontes de infecção do vírus Influenza A, subtipo H3N8, para o rebanho eqüino nacional. Para este fim, foi verificada a prevalência de anticorpos específicos para esse subtipo em eqüideos, recolhidos nas imediações de rodovias do Estado do Rio de Janeiro, pela Polícia Rodoviária Federal e posteriormente encaminhados ao curral de apreensão da UFRRJ, no período de 1999 a 2001. Os animais estudados foram provenientes dos seguintes municípios do Estado do Rio de Janeiro: Duque de Caxias, Petrópolis, Niterói, São Gonçalo, Itaguaí, Coroa Grande, Muriqui, Mangaratiba, Angra, Parati ,Teresópolis, Magé, Jardim Primavera, Três Córregos, Rio Bonito, São João de Meriti, Nilópolis, Nova Iguaçu, Belford Roxo, Queimados, Seropédica, Paracambi, Piraí, Retiro de Muriaé, Itaperuna, Nossa Senhora da Penha, São Joaquim, Italva, Cardoso Moreira Santa Rita, Campos, Além Paraíba, Sapucaia, Anta, Três Barras, Bemposta, Três Rios, Paraíba do Sul, Andrade Pinto, Maçambará, Vassouras, Barra do Piraí, Vargem Alegre, Volta Redonda, Barra Mansa, Três Rios, Casimiro de Abreu, Volta Redonda, Barra Mansa, Floriano, Resende, Penedo, Itatiaia, Porto Real Engenheiro Passos.

O teste de inibição da hemaglutinação (HI), empregado na pesquisa de anticorpos $\mathrm{H} 3 \mathrm{~N} 8$ específicos, foi realizado em placas de 96 cavidades, fundo em "U", conforme descrito por LOUREIRO et al. (2002). A amostra A/equine/Miami/63, que representa o subtipo $\mathrm{H} 3 \mathrm{~N} 8$, foi utilizada como antígeno viral no HI. Para tanto, este vírus foi inoculado pela via alantóica, em ovos embrionados $S P F$, com 8-10 dias de incubação e mantidos a $34^{\circ} \mathrm{C}$, por 72 horas. Após este período, o líquido alantóico colhido teve sua capacidade hemaglutinante aferida pelo teste da hemaglutinação (HA), foi aliquotado, inativado a $56^{\circ} \mathrm{C}$ por 30 minutos e congelado a $-20^{\circ} \mathrm{C}$, até o momento de uso. Para eliminação de inibidores da hemaglutinação e remoção de agentes hemaglutinantes inespecíficos, os soros foram tratados com Caolin a $25 \%$ e com suspensão de hemácias de galinha a $50 \%$, respectivamente (BALLOWS et al., 1996).

O levantamento sorológico retrospectivo indicou que $35,9 \%$ dos eqüinos errantes, provenientes dos diversos municípios do Estado do
Rio de Janeiro, apresentavam títulos para o subtipo H3N8. Não foi possível a obtenção, junto à Polícia Federal, da distribuição dos animais apreendidos, em relação aos municípios abrangidos pelas Delegacias da Polícia Rodoviária. A distribuição dos títulos encontrados nas espécies testadas pode ser observada na tabela 1 .

Em 1969, um grave surto de uma doença respiratória em cavalos do Jockey Clube Brasileiro, na cidade do Rio de Janeiro, despertou o interesse de um grupo de pesquisa que isolou e identificou o subtipo H3N8, a partir da secreção nasal de 10 animais com características clínicas sugestivas de Influenza. Estes resultados confirmaram os obtidos anteriormente, ratificando a importância deste subtipo no Estado do Rio de Janeiro (CUNHA et al., 1970). LOUREIRO et al., (2002), em um estudo piloto sobre a influenza eqüina em 242 animais trazidos ao curral de apreensão da UFRRJ, verificaram a circulação do subtipo $\mathrm{H} 3 \mathrm{~N} 8$ em $29,7 \%$ dos animais analisados. Em continuidade a este levantamento, realizou-se uma enquete, em um grupo distinto de 1106 eqüideos, visando ampliar a amostragem para maior significância dos resultados.

Os resultados sugerem que o vírus da influenza eqüina, subtipo H3N8, encontra-se presente e circulante na população eqüina do Estado do Rio de Janeiro, representando um risco à eqüinocultura brasileira. Esses resultados reforçam a importância do estabelecimento de uma rotina diagnóstica e epidemiológica para o vírus da influenza eqüina, alertando as autoridades responsáveis sobre o risco de possíveis surtos. Ressalta-se ainda a importância do monitoramento desta virose devido ao risco potencial para a saúde humana (MINUSE et al.,1965; SCHILD \& STUART-HARRIS, 1965; BEAN, 1992).

Tabela 1 - Resultados da prova de inibição da hemaglutinação na pesquisa de anticorpos para o vírus da influenza eqüina, subtipo H3N8.

\begin{tabular}{lccccccc}
\hline \multirow{2}{*}{ ESPÉCIES } & \multicolumn{4}{c}{ TÍTULOS (HI) } & POSITIVOS & NEGATIVOS \\
\cline { 2 - 4 } & 10 & 20 & 40 & 80 & $(+)$ & $(-)$ \\
\hline $\begin{array}{l}\text { Equus } \\
\text { caballus }\end{array}$ & 80 & 121 & 87 & 89 & 377 & 690 \\
Equus mus & 02 & 06 & 06 & 06 & 20 & 17 \\
Equus asinus & - & - & - & - & 0 & 02 \\
Totais (+/-) & & & & & $397(35,9 \%)$ & $709(64,1 \%)$ \\
Total de animais & & & \multicolumn{5}{c}{1106} \\
\hline
\end{tabular}




\section{REFERÊNCIAS}

ACHA, P.N.; SZYFRES, B. Zoonosis y enfermedades transmisibles comunes al hombre y a los animales. 3.ed. Washington : OPAS, 2003. 2.v, 488p.

ANDREWS, C. et al. Viruses of vertebrates. 4.ed. London: Balliére Tindall, 1978. 42p.

BALOWS, A. et al. Manual of clinical microbiology by American Society for Microbiology. 5.ed. Washington, 1996 p. 874 .

BEAN, W. et al. Evolution of the H3 influenza virus haemagglutinin from human and nonhuman hosts. Journal of Virology, v.66, p.1129-1138, 1992.

CUNHA, R.G. Isolamento do vírus de influenza A/Equi 2 no Estado da Guanabara. Revista Brasileira de Biologia, v.30, n.4, p.491-498, 1970 .

CUNHA, R.G. et al. Surto de gripe eqüina produzido por vírus de influenza A/Equi 2 no Estado do Rio de Janeiro, Brasil. Revista Brasileira de Biologia, v.8, n.3, p.88-91, 1986.
LOUREIRO, B.O. et al. Soroepidemiologia da Influenza eqüina, subtipo A/Eqüino-2 (H3N8) no Estado do Rio de Janeiro. Revista Brasileira de Medicina Veterinária, v.24, n.1, p.11-13, 2002.

LOUREIRO, B.O. Estudo de um surto de influenza eqüina ocorrido em 2001 no Estado do Rio de Janeiro mediante a caracterização do vírus e avaliação do esquema vacinal. 2004. 135f. Dissertação (Mestrado em Ciências na Área de Virologia) - Curso de Pós-graduação em Biologia Celular e Molecular, Instituto Oswaldo Cruz.

MILLER, W.M.C. Equine influenza. Further observations on the 'coughing' outbreak 1965. Veterinary Record, v.77, p.455-456, 1965.

MINUSE, E. et al. Studies of antibodies to 1956 and 1963 influenza viruses in horses and man. Journal of immunology, v.94, p.563-566, 1965

SCHILD, G.; STUART-HARRIS, C. Serological and epidemiological studies with influenza a viruses. Journal of Hygiene, v. 63, p.479-490, 1965

TIMONEY, P.J. Equine influenza. Comparative Immunology and Microbiology of Infectious Disease. v.19 n. 3, p.205-211, 1996. 